\title{
A Comparison of Two Brazilian Populations of Culex quinquefasciatus (Say, 1823) from Endemic and Non-endemic Areas to Infection with Wuchereria bancrofti (Cobbold, 1877)
}

\author{
Ana C Brito/ ${ }^{+}$, Paul Williams*, Gilberto Fontes, Eliana MM Rocha \\ Departamento de Patologia, Centro de Ciências Biológicas, Universidade Federal de Alagoas, Praça Afrânio \\ Jorge s/n, 57010-020 Maceió, AL, Brasil *Departamento de Parasitologia, Instituto de Ciências Biológicas, \\ Universidade Federal de Minas Gerais, Belo Horizonte, MG, Brasil
}

Culex quinquefasciatus is known to be an efficient insect host of Wuchereria bancrofti. In Brazil $\mathrm{Cx}$. quinquefasciatus is widely distributed throughout the country and is often abundant in and around human habitations. In contrast, Bancroftian filariasis is limited to three foci in Brazil. Experiments were undertaken to compare the vector capacities of $\mathrm{Cx}$. quinquefasciatus originating from Maceió (Alagoas), one of the endemic areas of $\mathrm{W}$. bancrofti infection in Brazil, and Belo Horizonte (Minas Gerais), a non endemic area. Laboratory-reared Cx. quinquefasciatus were dissected 20 days after blood feeding on microfilaraemic patients. Survival rates and the number of infective larvae that developed did not differ in female mosquitoes of different origins. Thus both populations of Culex were susceptible to infection with $\mathrm{W}$. bancrofti.

Key words: Culex quinquefasciatus - Wuchereria bancrofti - Bancroftian filariasis

Bancroftian filariasis has been more widespread in Brazil than it is today, when only three foci were known: Belém (Pará) (Fraiha-Neto 1993); Recife (Pernambuco) (Dreyer 1987, Medeiros et al. 1992) and Maceió (Alagoas) (Dreyer et al. 1991, Fontes et al. 1994). In each of these areas, these authors recorded natural infections of Wuchereria bancrofti.

Culex quinquefasciatus is widely distributed in tropical and subtropical areas. Because of the anthropophilic and endophilic blood feeding habits of female $C x$. quinquefasciatus it is closely associated with man and human habitations (Forattini et al. 1993, Consoli \& Lourenço-de-Oliveira 1994). Throughout much of its geographic range, $C x$. quinquefasciatus is of public health interest because it is a domestic pest but, in many places, it is a highly efficient insect host for the larval development of the filaria parasite W. bancrofti (Rosen 1955, Crans 1973, WHO 1980).

There are observations that $C x$. quinquefasciatus strains from filariasis free areas sup-

${ }^{+}$Corresponding author. Fax: +55-82-221.2501

Received 24 November 1995

Accepted 29 September 1996 port $W$. bancrofti development as well as that occurring in endemic areas. Magayuka and White (1972), studing colonies of Cx. pipiens fatigans from six localities in Kenya and Tanzania revealed high levels of susceptibility to infection with $W$. bancrofti. Similar results were reported by Partono (1979) using various Asian strains of Cx. quinquefasciatus. However, from Liberia where $C x$. quinquefasciatus is not considered to be an important filaria vector Zielke and Kuhlow (1977) reported low susceptibility of the local $C x$. quinquefasciatus to the local W. bancrofti.

In view of the extent of $C x$. quinquefasciatus in Brazil and the very limited studies about differences in mosquito susceptibility to the filarial parasite, experiments were undertaken to compare the vector susceptibility to $W$. bancrofti of $C x$. quinquefasciatus strains from filaria endemic and non endemic areas of Brazil. For this purpose two laboratory colonies of $C x$. quinquefasciatus were established. One colony derived from material colleted in Maceió (MAC), one of the foci of Bancroftian filariasis already mentioned. The other originated from a laboratory colony of $C x$. quinquefasciatus maintained in Belo Horizonte (BHZ), and established from specimens captured in that city. No autochthonous cases of Bancroftian filariasis have been recorded in Belo Horizonte, which is $1,900 \mathrm{~km}$ distant from Maceió. The studies were carried out in MAC. 


\section{MATERIALS AND METHODS}

Mosquitoes - Both colonies of mosquitoes were maintained in the same physical conditions, in an insectary with a temperature of $27 \pm 1^{\circ} \mathrm{C}$ and a humidity of $80 \pm 10 \%$ relative humidity. Larvae (and also pupae) were maintained in plastic containers with 21 of tap water. Larval food consisted of a $10 \%$ aqueous solution of powdered skimmed milk, given on alternate days. Pupae were collected every day. Plastic containers with pupae were transferred to net cages, where adults emerged. Adult mosquitoes were provided with an ad libidum source of a $10 \%$ aqueous glucose solution. Once a week, female mosquitoes had access to pigeons for blood feeding. The plastic containers used for maintaining pupae were also used as oviposition receptacles.

Human blood sources for mosquitoes - Fontes et al. (1994) undertook a blood survey to determine the number of residents in MAC with microfilaraemia. Of positive participants in that survey, three were asked to participate in the present experiment. The nature and purpose of the experiment were explained and each patient or its guardian gave written consent for participation. At the end of the experiment, the three patients were offered a full course of treatment. The three patients were life-long residents of MAC, one female, two males, with estimated ages of 16-19 years. One had a microfilaraemia of $700 \mathrm{microfilariae} / \mathrm{ml}$, the second had $450 \mathrm{mf} / \mathrm{ml}$, and the third had $17 \mathrm{mf} / \mathrm{ml}$. Microfilaria densities were determined by the Nucleopore ${ }^{\hat{a}}$ filtration method (Chularerk \& Desowitz 1970) and were carried out immediately after exposure to mosquito bites.

Infection of mosquitoes - Female mosquitoes used in experiments were 2-10 days post-eclosion and were deprived of sugar meals for $24 \mathrm{hr}$ before blood feeding. Blood meals were offered for 1530 min between 22:00 and 24:00 hr, coincidental with the peak of microfilarial periodicity in MAC (Rocha et al. 1991), and with the peak of female Cx. quinquefasciatus biting activity (Rachou 1956).

One hundred and eighty-one females of the BHZ colony and 116 of the MAC colony blood fed on the microfilaraemic volunteers. On five occasions a total of 240 females from MAC were allowed to blood feed on an uninfected volunteer, who lived in the endemic area. For this the amicrofilaremic status were determined prior the feeding experiment by the Nucleopore ${ }^{a}$ filtration method using $1 \mathrm{ml}$ of venous blood. Also, $30 C x$. quinquefasciatus were killed immediately after feeding an amicrofilaremic person and dissected to detect microfilariae by examination of the mid- gut contents. After infection, females were maintained in individual cages in the insectary conditions already mentioned. The number of dead mosquitoes was recorded daily. Specimens that survived for 20 days after exposure to infection, were individually dissected. The head, thorax and abdomen were teased apart in phosphate buffered saline and examined microscopically for third-stage larvae.

Assessment of results - Dissection of specimens on the 20th day after exposure to infection corresponds to the time needed in MAC for microfilariae of $W$. bancrofti to develop to the third larval stage $\left(\mathrm{L}_{3}\right)$ (Brito 1995). Comparison of the susceptibility of the two lines of $C x$. quinquefasciatus was assessed by equations proposed by Wharton (1960) and Ramachandran (1970).

$$
\begin{aligned}
& \text { Survival rate }=\frac{\text { No. of mosquitoes surviving for } 20 \text { days }}{\text { No. of blood feed mosquitoes }} \\
& \text { Infectivity rate }=\frac{\text { No. of mosquitoes containing } \mathrm{L}_{3} \text { after } 20 \text { days }}{\text { No. of mosquitoes surviving for } 20 \text { days }} \\
& \text { Intensity of infection }=\frac{\text { No. of mature } \mathrm{L}_{3}}{\text { No. of mosquitoes with } \mathrm{L}_{3}}
\end{aligned}
$$

Statistical analysis - Chi-squared nonparametric tests with $\mathrm{p}$ values $<0.05$ were considered statistically significant.

\section{RESULTS}

The results are summarized in the Table. The survival rates, infectivity rates and intensities of infection have been summed herein although the three volunteers had widely differing microfilaraemias. In addition to the data presented, it is necessary to record that the survival rate of female mosquitoes that blood feed on an uninfected person was 0.78 , because 164 females survived after 20 days to infection. This was lower than the survival rates in mosquitoes exposed to infection, but the differences were not statistically significant ( $\mathrm{p}>0.05)$.

The $C x$. quinquefasciatus from non endemic area was also susceptible to infection with $W$. bancrofti. The infectivity rate in the BHZ line was significantly lower than that of the MAC line. However, both lines of mosquito supported the development of filarial larvae to the third (presumably infective) larval stage. Intensity of infections in the two mosquito lines were not statistically different.

\section{DISCUSSION}

Vector competence with regard to $W$. bancrofti can vary in $C x$. quinquefasciatus populations from different geographical areas (Janousek \& Lowrie 
TABLE

Results of exposure to infection with Wuchereria bancrofti in Culex quinquefasciatus originating from Belo Horizonte (BHZ) or Maceió (MAC)

\begin{tabular}{|c|c|c|c|c|c|c|c|}
\hline \multirow{2}{*}{$\begin{array}{l}\text { Source of } \\
\text { blood meal }\end{array}$} & \multirow{2}{*}{$\begin{array}{c}\text { Mosquito } \\
\text { line }\end{array}$} & \multicolumn{3}{|c|}{ No. of mosquitoes } & \multirow{2}{*}{$\begin{array}{l}\text { Survival } \\
\text { rate }\end{array}$} & \multirow{2}{*}{$\begin{array}{l}\text { Infectivity } \\
\text { rate }\end{array}$} & \multirow{2}{*}{$\begin{array}{c}\text { Intensity of } \\
\text { infection } \\
\left(\mathrm{L}_{3} / \text { mosq. }\right)\end{array}$} \\
\hline & & Fed & Dissected & $\begin{array}{l}\text { Infected } \\
\text { with } \mathrm{L}_{3}\end{array}$ & & & \\
\hline \multirow{2}{*}{ Volunteer 1} & BHZ & 38 & 20 & 16 & 0,52 & 0,80 & 2,62 \\
\hline & MAC & 55 & 47 & 31 & 0,85 & 0,66 & 2,48 \\
\hline \multirow{2}{*}{ Volunteer 2} & BHZ & 106 & 98 & 21 & 0,92 & 0,21 & 1,95 \\
\hline & MAC & 48 & 39 & 19 & 0,81 & 0,48 & 1,89 \\
\hline \multirow{2}{*}{ Volunteer 3} & BHZ & 37 & 35 & 1 & 0,94 & 0,03 & 1,00 \\
\hline & MAC & 33 & 30 & 1 & 0,91 & 0,03 & 1,00 \\
\hline \multirow{2}{*}{ Total } & BHZ & 181 & 153 & 38 & $0,84^{a}$ & $0,25^{b}$ & $2,21^{a}$ \\
\hline & MAC & 136 & 116 & 51 & $0,85^{a}$ & $0,44^{b}$ & $2,24^{a}$ \\
\hline
\end{tabular}

$a$ : not statistically different ( $>0.05) ; b$ : statistically different $\left(c^{2}=10.90 ; \mathrm{p}<0.05\right)$.

1989). This is probably explained by genetic differences since MacDonald (1967) found that mosquito susceptibility to filariae is governed by inheritable factors. The present results provide evidence of differences in developmental rates filarial larvae of BHZ and MAC lines of $C x$. quinquefasciatus. The lower infectivity rate in the $\mathrm{BHZ}$ line might suggest that the MAC line of $C x$. quinquefasciatus is better adapted to the requirements of the local strain of $W$. bancrofti than is the BHZ line of mosquitoes. Although this topic needs further study, both colonies apparently carry the gene(s) to support $W$. bancrofti development.

The focus of lymphatic filariasis in MAC is small and occupies only a part of the city (Fontes et al. 1994). The interesting feature is that $C x$. quinquefasciatus from BHZ, almost 2,000 km from MAC, are virtually as susceptible to infection with the MAC strain of $W$. bancrofti.

Dynamics of transmission is a very complex subject in lymphatic filariasis, but parameters such as the presence of suitable vectors, susceptible human population and environment are important factors that influence distribution of this disease (Vanamail et al. 1990). Although the relative inefficiency of filarial transmission and the complexity of the parasite life cycle, filariasis prevalence and distribution is still high in developing world. Migrations of infected individuals to places with mosquitoes of a good transmitting species is a potential danger that contribute to introduction of Bancroftian filariasis into non endemic areas. In Sri Lanka infected migrants originated new filaria focus in areas where there were no lymphatic filariasis (WHO 1984). A comparable risk has been proved to exist with regard to another filaria infection - onchocerciasis - in Brazil. Shelley (1988) published a map of the distribution of human onchocerciasis in Latin America, up to 1987. This shows an isolated focus of the disease in Minaçu well south of the Brazilian focus of the disease. A single autochthonous case was reported (Gerais \& Ribeiro 1986), and was ascribed to the return of tin miners to the State of Goiás after visiting the hyperendemic area. Internal migration within Brazil could facilitate the spread of $W$. bancrofti to places where lymphatic filariasis has never existed or from where it has been erradicated.

\section{ACKNOWLEDGMENTS}

To the volunteers who participated in this study. To Dr Rotraut AGB Consoli, Centro de Pesquisas René Rachou-FIOCRUZ, Belo Horizonte, Minas Gerais, Brazil, who supplied the BHZ line of mosquitoes. To Dr João de Freitas for advice concerning ethical question. To students, for technical assistance.

\section{REFERENCES}

Brito AC 1995. Estudo quantitativo da ingestão $e$ desenvolvimento da Wuchereria bancrofti em Culex quinquefasciatus (Say, 1823) alimentados em indivíduos microfilarêmicos com diferentes parasitemias. MSc Thesis, Universidade Federal de Minas Gerais, Belo Horizonte, MG, 166 pp.

Chularerk P, Desowitz RS 1970. A simplified membrane filtration technique for the diagnosis of microfilaremia. J Parasitol 53: 623-24. 
Consoli RAGB, Lourenço-de-Oliveira R 1994. Principais mosquitos de importância sanitária no Brasil. Rio de Janeiro, FIOCRUZ, 228 pp.

Crans WJ 1973. Experimental infection of Anopheles gambiae and Culex pipiens fatigans with Wuchereria bancrofti in Coastal Africa. J Med Entomol 10: 189-193.

Dreyer G 1987. Filariasis programme-Recife-Brasil. Mem Inst Oswaldo Cruz 82: 359-360.

Dreyer G, Medeiros Z, Beliz F, Vergetti G, Vergetti A, Café T, Fontes G 1991. Autochthonous Wuchereria bancrofti microfilaraemia in the city of MaceióAlagoas-Brazil. Mem Inst Oswaldo Cruz, 86: 495496.

Fontes G, Brito AC, Calheiros CML, Antunes CMF, Rocha EMM 1994. Present status of bancroftian filariasis in Maceió, State of Alagoas, Brazil. Cad Saúde Públ 10: 293-299.

Forattini OP, Kakitani I, Massad E, Marucci D 1993. Studies on mosquitoes (Diptera: Culicidae) and anthropic environment. 4-Survey of resting adults and synanthropic behavior in South-Eastern, Brasil. Rev Saúde Públ 27: 398-411.

Fraiha-Neto H 1993. Bancroftian filariasis In Belém, Pará State. Possibilities for eradication by introducing modern methods of control for Culex quinquefasciatus. Cad Saúde Públ 9: 458-465.

Gerais BB, Ribeiro TC 1986. Onchocerca volvulus Primeiro caso autoctone da região Centro-Oeste. Rev Soc Bras Med Trop 19: 68.

Janousek TE, Lowrie Jr RC 1989. Vector competency of Culex quinquefasciatus (Haitian strain) following infection with Wuchereria bancrofti. Trans $R$ Soc Trop Med Hyg 83: 679-680.

MacDonald WW 1967. The influence of genetic and other factors on vector susceptibilty to parasites, $\mathrm{p}$. 567-584. In JW Wrigth, R Pal (eds), Genetics of insect vectors of disease, Amsterdam, Elsevier.

Magayuka SA, White GB 1972. Hybrid compatibilities and susceptibility of Culex pipiens fatigans Wied. to Wuchereria bancrofti (Cobbold) In East Africa. Bull WHO 46: 801-805

Medeiros Z, Dreyer G, Andrade LD, Pires ML, Mendes
J, Pimentel R 1992. Wuchereria bancrofti microfilarial density of autochthonous cases and natural Culex infectivity rates in Northeast, Brazil. J Trop Med Hyg 95: 214-217.

Partono F 1979. Studies on the susceptibility of Culex pipiens fatigans from non-endemic filarial areas to urban Wuchereria bancrofti. Ann Trop Med Parasitol 73: 79-81.

Rachou RG 1956. Transmissores da filariose bancroftiana no Brasil. Rev Brasil Malariol D Trop 8: 267-268.

Ramachandran CP 1970. A guide to methods and techniques in filariasis investigations. Filar Res Off Inst Med Res Kuala Lumpur, 39 pp.

Rocha EMM, Fontes G, Vergetti JG, Santos ACB, Fireman FAT, Dreyer G 1991. Periodicidade de microfilárias de Wuchereria bancrofti em filarióticos autóctones de Maceió-AL. Rev Inst Med Trop $S$ Paulo 33: 35.

Rosen L 1955. Observations on the epidemiology of human filariasis in French Oceania. Am J Hyg 61: 219-248.

Shelley AJ 1988. Vector aspects of the epidemiology of onchocerciasis in Latin America. Ann Rev Entomol 33: 337-366.

Vanamail P, Subramanian S, Das PK, Pani SP, Rajagopalan PK 1990. Estimation of fecundic life span of Wuchereria bancrofti from longitudinal study of human infection in an endemic area of Pondicherry (south India). Indian J Med Res 91: 293 297.

Wharton RH 1960. Studies on filariasis in Malaya: field and laboratory investigations of the vectors of a rural strain of Wuchereria bancrofti. Ann Trop Med Parasitol 54: 78-91.

WHO 1980. Biology and control of Culex pipiens quinquefasciatus Say, 1823 (Diptera, Culicidae) with special reference to Africa. No. 781, 40 pp.

WHO 1984. Filariasis linfatica. Cuarto informe del Comité de Expertos de la OMS en Filariasis, 119 pp.

Zielke E, Kuhlow F 1977. On the inheritance of susceptibility for infection with Wuchereria bancrofti in Culex pipiens fatigans. Trop Med Parasitol 28: 6870. 